\title{
Patients with Severe Poststroke Fatigue Show a Psychosocial Profile Comparable to Patients with Other Chronic Disease: Implications for Diagnosis and Treatment
}

\author{
Aglaia M. E. E. Zedlitz, ${ }^{1,2}$ Anne J. M. A. Visser-Meily, ${ }^{3,4}$ Vera P. Schepers, ${ }^{3,4}$ \\ Alexander C. H. Geurts, ${ }^{5,6}$ and Luciano Fasotti ${ }^{1,2}$ \\ ${ }^{1}$ Donders Centre for Cognition, Radboud University Nijmegen, $6500 \mathrm{HE}$ Nijmegen, The Netherlands \\ ${ }^{2}$ Sint Maartenskliniek Research, Development and Education, 6500 GM Nijmegen, The Netherlands \\ ${ }^{3}$ Rudolf Magnus Institute of Neuroscience, University Medical Center Utrecht, 3508 GA Utrecht, The Netherlands \\ ${ }^{4}$ Center of Excellence for Rehabilitation Medicine Utrecht, Rehabilitation Center De Hoogstraat, 3583 TM Utrecht, The Netherlands \\ ${ }^{5}$ Nijmegen Centre for Evidence Based Practice, Radboud University Nijmegen Medical Centre, 6500 HB Nijmegen, The Netherlands \\ ${ }^{6}$ Department of Rehabilitation, Radboud University Nijmegen Medical Centre, Nijmegen, 6500 HB Nijmegen, The Netherlands
}

Correspondence should be addressed to Aglaia M. E. E. Zedlitz, a.zedlitz@donders.ru.nl

Received 4 August 2011; Accepted 17 September 2011

Academic Editors: A. Conti, A. Karni, and K. W. Lange

Copyright ( 2011 Aglaia M. E. E. Zedlitz et al. This is an open access article distributed under the Creative Commons Attribution License, which permits unrestricted use, distribution, and reproduction in any medium, provided the original work is properly cited.

\begin{abstract}
Objective. To obtain a psychosocial profile of patients with poststroke fatigue (PSF), which could aid in optimizing treatment strategies. Methods. Eighty-eight outpatients with severe PSF measured with the Checklist Individual Strength-fatigue subscale (CIS-f) and the Fatigue Severity Scale (FSS) were selected. Depression and anxiety, psychological distress, coping, social support, and self-efficacy of this group were compared to reference groups of healthy controls and patients with other chronic diseases. Associations between psychosocial characteristics and fatigue were calculated. Results. Compared to healthy controls, patients with PSF reported more psychological distress, less problem-focused coping, and more positive social support. Minor or no differences were found in comparison with other chronic patients. The CIS-f correlated with somatic complaints and the FSS with cognitive complaints. Conclusion. Patients with PSF show a psychosocial profile comparable to patients with other chronic disease. Implications for diagnosis and treatment are discussed.
\end{abstract}

\section{Introduction}

In recent years, researchers have become increasingly interested in one of the most common and persisting complaints after stroke, that is, poststroke fatigue (PSF). PSF is best described as a feeling of early exhaustion with weariness, lack of energy and aversion to effort [1] that develops during physical or mental activity and is usually not ameliorated by rest $[2,3]$. The percentages of patients reporting fatigue after stroke range from $38 \%$ to $77 \%$ [4], and these percentages do not seem to decline in the chronic stage [4-6]. Furthermore, PSF appears to be related to higher mortality rates and poorer rehabilitation outcomes [7]. However, the pathogenesis of PSF is still poorly understood and, until now, effective treatments are still lacking $[4,8]$.
Although the mechanisms leading to PSF are still elusive, its origin is believed to be multifactorial [4]. PSF may be a direct result of organic brain damage [9], as it has often been reported in other types of brain disease, such as traumatic brain injury [10]. However, only a few associations of fatigue with biological markers have been reported in the stroke population [4]. In other words, although stroke severity may play a role, there is little evidence linking lesion size or location to PSF $[3-5,11]$. The origin of PSF could also be related to psychosocial factors, which has been the focus of numerous studies (see Lerdal et al., 2009, [4] for an overview). Of all psychosocial factors, the most investigated are depression, anxiety, coping skills, social support, and selfefficacy. Nevertheless, also in this area, unequivocal findings are scarce [4]. 
Because fatigue is generally considered as a symptom of depression, an overlap between both phenomena seems undeniable $[1,4,9]$. Indeed, an association between fatigue and depressive symptoms is a consistent finding in the literature not only in stroke patients $[2,5-7,11-14]$, but also in patients with traumatic brain injury [10] and in otherwise healthy subjects $[10,13]$. Yet, in those studies that specifically looked at patients who suffer from depressive symptoms and/or fatigue, a clear dissociation between the two phenomena was also present with groups of patients reporting just fatigue or just depression $[5,6,11,15]$. The same seems to be true for anxiety [7]. The studies that have examined coping style, self-efficacy, and social support suggest that emotion-oriented coping $[2,16]$, locus of control directed to powerful others [5], and lack of social support [4] are also associated with PSF. These studies are, however, few in number and cross-sectional in design and did not specifically focus on patients for rehabilitation purposes. As a result, the nature of the psychosocial profile of patients suffering from PSF is still largely unknown, providing only scant clues for optimizing the treatment of PSF $[4,8]$.

The aim of this study was to compare a psychological and social profile of stroke patients, with severe PSF selected for rehabilitation, to the one of healthy control subjects and patients with other chronic diseases and to investigate the strength of the association between fatigue and several psychosocial variables. Knowledge about this psychosocial profile can help to optimize PSF treatment.

\section{Methods}

2.1. Subjects. Data were gathered from patients with PSF who participated in a larger multicenter study (COGRAT: Effectiveness of Cognitive and Graded Activity Training on PSF [17]). In this study, 231 patients were recruited via their treating physicians and psychologists $(n=64)$, through an article about the COGRAT study in various newspapers $(n=151)$, or based on their consent for renewed contact given in earlier studies $(n=16)$. The study was approved by the local ethics committee and all eligible subjects signed an informed consent.

For the COGRAT study outpatients in the chronic stage of stroke (at least 4 months after stroke) were identified according to the following criteria: (1) age between 18 and 70; (2) last stroke episode longer than 4 months ago (either cerebral infarction, or intracerebral or subarachnoid hemorrhage; single or recurrent stroke); (3) severe fatigue (Checklist Individual Strength 20R-Fatigue subscale [18] $\geq 40$ ); (4) ability to walk independently. Patients were excluded from the study if they had (1) severe visual hemineglect, Behavioural Inattention Test $\leq 129$ [19], (2) severe memory deficits (Rivermead Behavioural Memory Test [19] screening score $<8$ ), (3) executive impairments (Behavioural Assessment of the Dysexecutive Syndrome [19] $<$ borderline), (4) moderate to severe aphasia (Token Task $[19]>12),(5)$ severe cardiac or pulmonary disease, or (6) comorbid depression (Hospital Anxiety and Depression Scale depression scale $>10$ ). If the HADS depression scale score was between 8 and 10, a clinical interview (MINI DSMIV [20]) was conducted to exclude patients with clinical depression.

Of the 124 excluded patients, 47 (54\%) were not severely fatigued and 21 had too high levels of depression. The remaining 56 patients met one or more other exclusion criteria, such as memory deficits, mobility deficits, or aphasia. Nineteen more patients withdrew their consent before completion of assessment. Thus, 88 patients (38\%) were finally included. These participants did not differ significantly with regard to age and gender (alpha $=0.05$ ) from the nonparticipants and those excluded based on too high levels of depression.

2.2. Demographic and Clinical Assessment. Data on age, sex, marital status, educational level, and stroke type and side were obtained from the patients and their medical records. Severity of paresis was assessed with the Motricity Index (MI) of the affected lower extremity [21]. The MI was recorded because lower extremity paresis is strongly related to balance [22] and mobility after stroke [23], and mobility might be associated with poststroke depression [24].

2.3. Assessment of Fatigue. Two widely used and wellvalidated measures of fatigue were used in this study, the subscale fatigue of the Checklist Individual Strength 20R (CIS-f) [18] and the Fatigue Severity Scale (FSS) [25]. The CIS- $f$ consists of 8 out of 20 items of the questionnaire, asking about fatigue severity in the two weeks before the assessment, to be indicated on a 7-point Likert scale (range $8-56$ ). Patients with a score $\geq 40$ on this subscale were defined as being severely fatigued [6]. In the FSS, individuals rate their agreement with nine statements on a 7-point Likert scale concerning fatigue severity, frequency, and impact on daily life. The mean score (range 1-7) is then calculated. The threshold for moderate to high impact of fatigue using the FSS is commonly set at either 4 or 5 [26].

2.4. Psychosocial Assessment. To study the psychosocial characteristics of patients with PSF, self-report questionnaires regarding depression, anxiety, psychological distress, coping, social support, and self-efficacy were used. Depression and anxiety were measured with the Hospital Anxiety and Depression Scale (HADS) [27]. The HADS is a 14 item self-report measure, with seven items forming a depression subscale and another seven constituting an anxiety subscale. Each item is rated on a four-point scale, ranging from 0 to 3 , with 3 reflecting the highest distress. Total scores for each subscale range from 0 to 21 and are categorized as normal (07), mild (8-10), moderate (11-14), or severe (15-21) [28].

The Symptom Checklist-90 (SCL) [29] measures psychological distress [30]. The scale consists of 90 items scored on a 5-point Likert scale. Nine psychopathology scores can be derived and the total score (GSI) reflects a global severity index of psychological distress. Furthermore, a personality severity index (PSI) to assess personality problems can be calculated [31]. This is done by transferring raw scores to 
SCL-90R scales, and then comparing the mean scores of the scales interpersonal sensitivity, hostility, and paranoid ideation to the mean value of the remaining scales.

Coping strategies were assessed with the coping inventory for stressful situations (CISS) [32]. Forty-eight items are scored on a 5-point Likert scale, resulting in three subscales: Problem-focused coping, Emotion-focused coping, and Avoidance-focused coping.

Social support was assessed with the Social support list (SSL-12) [33] that consists of twelve statements regarding perceived positive and negative social support from the primary social network. Positive support is described by three subscales: everyday support, support in problem situations, and esteem support.

The Self-Efficacy Scale (SES) was used to assess the sense of control in relation to fatigue complaints [34]. It consists of 5 statements each scored on a 5-point scale. The total scores ranges from 5 to 25 , with a higher score reflecting more sense of control.

2.5. Data Analysis. Descriptive statistics (i.e., mean and standard deviation (SD)) were calculated for all psychosocial characteristics. These values were compared to known reference values and derived Z-scores from healthy controls and patient populations (General practice, traumatic brain injury, chronic pain, Multiple Sclerosis, Parkinson, Cancer, Rheumathoid Arthritis, and Chronic Fatigue Syndrome) reported in the literature $[28,29,32,33,35-37]$. Based on these Z-scores different categories were labeled as follows: $<-1.28=$ very low,$<-.84=$ low,$<-.525=$ below average, between -.525 and $.525=$ average, $>.525=$ above average, $>.84$ high and $>1.28$ very high.

The presence of personality problems was determined by calculating a PSI from the raw scores of the SCL. Associations between the CIS-f-FSS fatigue scales and gender, marital status, lesion characteristics, and PSI were calculated with $\chi_{2}$ analyses. Spearmen rank correlations were calculated with the ordinal demographical, stroke, and psychosocial characteristics. Then a stepwise multiple regression analysis was performed on the variables significantly associated with fatigue to establish their unique contribution. All data analyses were computed with SPSS version 17.0, using Holm's correction to adjust for multiple analyses [38].

\section{Results}

Demographic data, severity of paresis, fatigue scores, and stroke characteristics are summarized in Table 1. Scores on both fatigue scales indicated on average "severe fatigue." On the CIS-f, $92.0 \%$ of the subjects scored above 40 . On the FSS, $92.0 \%$ scored above 4 and $69.3 \%$ above 5 . The mean MI was 90.2 indicating on average mild lower extremity paresis. Mean postonset time since last stroke was 4.3 years, which did not differ significantly between single and recurrent strokes.

3.1. Psychosocial Characteristics. To investigate the psychosocial characteristics of our patients, the scores were compared
TABLE 1: Demographic data, severity of paresis, stroke data and fatigue scores $(n=88)$.

\begin{tabular}{|c|c|}
\hline \multicolumn{2}{|l|}{ Demographics } \\
\hline Age, mean (SD) & $54.6(8.8)$ \\
\hline Gender, male, no. (\%) & $46(52.3 \%)$ \\
\hline Living together/married, no. (\%) & $71(80.7 \%)$ \\
\hline $\begin{array}{l}\text { Educational level, median }(\mathrm{SD}),(1= \\
\text { low to } 7=\text { high })\end{array}$ & $5(1.2)$ \\
\hline \multicolumn{2}{|l|}{ Severity of paresis } \\
\hline Motricity Index, mean (SD) & $90.2(13.6)$ \\
\hline \multicolumn{2}{|l|}{ Stroke } \\
\hline Time since last lesion, mean (SD) & $4.3(5.3)$ \\
\hline Single Stroke, no. (\%) & $67(76.1 \%)$ \\
\hline Ischemic stroke ${ }^{\mathrm{a}}$, no. $(\%)$ & $64(72.7 \%)$ \\
\hline Hemorrhage $^{\mathrm{b}}$, no. $(\%)$ & $6(6.82 \%)$ \\
\hline Subarachnoid hemorrhage, no. (\%) & $9(10.2 \%)$ \\
\hline Mixed $^{c}$, no. $(\%)$ & $4(4.5 \%)$ \\
\hline \multicolumn{2}{|l|}{ Fatigue } \\
\hline CIS-f, mean (SD) & $45.4(5.6)$ \\
\hline FSS, mean (SD) & $5.2(1.0)$ \\
\hline \multicolumn{2}{|c|}{$\begin{array}{l}\text { CIS-f: Checklist Individual Strength subscale fatigue. } \\
\text { FSS: Fatigue Severity Scale. } \\
\text { aCVA category: } 18 \text { left hemispheric, } 44 \text { right hemispheric, } 4 \text { infratentorial, } \\
\text { and } 3 \text { bilateral. }\end{array}$} \\
\hline
\end{tabular}

to reference values obtained from norm groups of healthy controls and patient groups from general health practice and with various chronic afflictions (Table 2). The HADS anxiety scores were comparable to other patient groups but high when compared to the general population. Using the Z-score derived, abovementioned categories [28], $60.2 \%$ of the patients had normal, $17 \%$ mild, $18.2 \%$ moderate, and $4.5 \%$ severe scores on HADS-anxiety. On the depression subscale of the HADS, we found high scores compared to both the general population and general practice patients. Still, $64.8 \%$ of our subjects had normal and the remaining $35.2 \%$ only mild depressive symptoms. The scores on the SCL were generally high compared to healthy controls, but in comparison to other patient groups the SCL scores were average, except for the subscale "Obsessive Compulsive" which was above average, reflecting more subjective cognitive complaints. The PSI is a categorical value and could therefore not be compared to reference values. Nevertheless, the incidence rate indicated that $93.2 \%$ of the patients were free from personality problems.

As for coping strategies, our patients showed slightly lower levels of problem-focused and avoidance strategies than healthy controls. However, in comparison to other patient groups, they scored average or above average for all strategies. Furthermore, our patients received more positive social support with as many negative social interactions compared to healthy controls and other patient groups. Compared to patients with chronic fatigue syndrome (CFS) 
TABLE 2: Means and standard deviations of baseline psychosocial characteristics of PSF patients in comparison with healthy controls and patients with other chronic disease $(n=88)$.

\begin{tabular}{|c|c|c|c|c|}
\hline Scale at inclusion & $\begin{array}{l}\text { Mean (SD) } \\
\text { Study group }\end{array}$ & Healthy controls & \multicolumn{2}{|c|}{ Patient groups } \\
\hline \multicolumn{5}{|l|}{ Psychosocial characteristics } \\
\hline HADS & & $\begin{array}{l}\text { General population } 57-65 \\
\text { years }(n=1901)[35]\end{array}$ & $\begin{array}{l}\text { General practice } \\
\text { patients }(n=112)[35]\end{array}$ & $\begin{array}{l}\text { Traumatic brain } \\
\text { injury patients } \\
(n=100)[28]\end{array}$ \\
\hline Anxiety & $7.27(3.76)$ & High & Average & Average \\
\hline Depression & $7.05(2.37)$ & High & High & Average \\
\hline Psychological distress: SCL & & $\begin{array}{l}\text { Healthy controls } \\
(n=2092)[29]\end{array}$ & $\begin{array}{l}\text { General practice } \\
\text { patients }(n=920)[29]\end{array}$ & $\begin{array}{l}\text { Chronic pain } \\
\text { patients } \\
(n=2461)[29]\end{array}$ \\
\hline Anxiety & $15.08(4.84)$ & Above average/high & Average & Average \\
\hline Phobic anxiety & $9.13(3.06)$ & Above average/high & Average & Average \\
\hline Depression & $27.44(7.80)$ & High & Average & Average \\
\hline Somatic & $22.25(6.61)$ & High & Average & Average \\
\hline Obsessive-compulsive & $20.51(6.47)$ & Very high & Above average & Above average \\
\hline Interpersonal sensitivity & $26.98(8.95)$ & Average & Average & Average \\
\hline Hostility & $8.36(2.45)$ & Average & Average & Average \\
\hline Sleep disturbances & $6.74(3.21)$ & Above average/high & Average & Average \\
\hline Total (GSI) & $149.00(35.80)$ & High & Average & Average \\
\hline Coping styles (CISS) & & $\begin{array}{l}\text { Working adults }(n=683) \\
{[32]}\end{array}$ & $\begin{array}{l}\text { Multiple Sclerosis } \\
\text { patients }(n=96)[32]\end{array}$ & $\begin{array}{l}\text { Parkinson patients } \\
(n=75)[32]\end{array}$ \\
\hline Problem focused & $51.89(10.98)$ & Low & Average & Above average \\
\hline Emotion-oriented coping & $35.75(10.51)$ & Average & Average & Above average \\
\hline Avoidance & $40.55(10.66)$ & Below average & Above average & Above average \\
\hline Social support (SSL-12) & & $\begin{array}{l}\text { Healthy elderly }(n=5279) \\
{[33]}\end{array}$ & $\begin{array}{l}\text { Cancer patients } \\
(n=475)[36]\end{array}$ & $\begin{array}{l}\text { Rheumatoid } \\
\text { arthritis patients } \\
(n=246)[36]\end{array}$ \\
\hline Everyday support & $10.69(2.08)$ & Above average & & \\
\hline Support in problem situations & $9.76(2.24)$ & High & & \\
\hline Esteem support & $10.35(2.10)$ & High & & \\
\hline Negative social interactions & $9.91(2.92)$ & Average [36] & Average & Average \\
\hline Self-efficacy (SES) & & & $\begin{array}{l}\text { Chronic fatigue } \\
\text { syndrome patients } \\
(n=292)[37]\end{array}$ & \\
\hline Self efficacy & $16.57(3.32)$ & & Above average & \\
\hline
\end{tabular}

[37], they reported to be "more in control" when assessed with the SES.

\subsection{Associations of Demographic, Clinical, and Psychosocial} Characteristics with Fatigue. Table 3 shows the correlation coefficients of demographic, clinical, and psychosocial characteristics with both fatigue scores. No associations with either fatigue scale (CIS-f or FSS) were found for demographic data, stroke characteristics, or severity of paresis (MI).

The CIS-f scale showed a statistically significant but moderate association with SCL-somatic and SCL-depression. The FSS was only related to the Obsessive Compulsive subscale of the SCL. No other significant associations were found for any psychosocial measure. 
TABle 3: Correlation coefficients of demographic, clinical, and psychosocial characteristics with PSF $(n=88)$.

\begin{tabular}{lll}
\hline & CIS-f & FSS \\
\hline Demographic data & & \\
Age $^{2}$ & n.s. & n.s. \\
Gender $^{1}$ & n.s. & n.s. \\
Marital status $^{1}$ & n.s. & n.s. \\
Educational level $^{2}$ & n.s. & n.s. \\
\hline Stroke characteristics $^{\text {Single or recurrent stroke }}{ }^{1}$ & & \\
Lesion side of last stroke $^{1}$ & n.s. & n.s. \\
Time since last stroke $^{2}$ & n.s. & n.s. \\
\hline Severity of paresis $(M I)^{2}$ & n.s. & n.s. \\
\hline
\end{tabular}

Psychosocial characteristics

Anxiety and depression (HADS) ${ }^{2}$

\begin{tabular}{lll} 
HADS-anxiety & n.s. & n.s. \\
HADS-depression & n.s. & n.s. \\
\hline
\end{tabular}

\begin{tabular}{|c|c|c|}
\hline \multicolumn{3}{|l|}{ Psychological distress $(S C L)^{2}$} \\
\hline Anxiety & n.s. & n.s. \\
\hline Phobic anxiety & n.s. & n.s. \\
\hline Depression & $0.35^{*}$ & n.s. \\
\hline Somatic & $0.53^{*}$ & n.s. \\
\hline Obsessive compulsive & n.s. & $0.36^{*}$ \\
\hline Intrapersonal sensitivity & n.s. & n.s. \\
\hline Hostility & n.s. & n.s. \\
\hline Sleep disturbances & n.s. & n.s. \\
\hline Total (GSI) & $0.34^{*}$ & n.s. \\
\hline Personality problems $(\mathrm{PSI})^{1}$ & n.s. & n.s. \\
\hline \multicolumn{3}{|l|}{ Coping $(\text { CISS })^{2}$} \\
\hline Problem-focused coping & n.s. & n.s. \\
\hline Emotion-oriented coping & n.s. & n.s. \\
\hline Avoidance & n.s. & n.s. \\
\hline Distraction seeking & n.s. & n.s. \\
\hline Company seeking & n.s. & n.s. \\
\hline \multicolumn{3}{|l|}{ Social support $(S S L-I-N)^{2}$} \\
\hline Total positive support & n.s. & n.s. \\
\hline Negative social interactions & n.s. & n.s. \\
\hline Self-efficacy $(S E S)^{2}$ & n.s. & n.s. \\
\hline \multicolumn{3}{|c|}{$\begin{array}{l}{ }^{1} \chi^{2} \text { analyses (categorical data) } \\
{ }^{2} \text { Spearman rank correlation coefficients } \\
\text { n.s.: not significant } \\
{ }^{*} \text { significant at Holm's correction }(P<.0011) \\
\text { CIS-f: Checklist Individual Strength fatigue severity subscale } \\
\text { FSS: Fatigue Severity Scale }\end{array}$} \\
\hline
\end{tabular}

Multiple regression analysis was performed only for the CIS-f with associated variables, since the FSS correlated with just one psychosocial variable (Table 3). SCL-Som significantly predicted CIS-f scores, $\beta=.54, t(86)=5.89$, $P<.001$. SCL-Dep did not add significantly to the model $(P=.78)$ with no concerns for multicolinearity $(\mathrm{VIF}=1.56$, tolerance $=.64)$.

\section{Discussion}

The aim of this investigation was to obtain a psychosocial profile of patients suffering from severe PSF in order to tease out options for the rehabilitation of fatigue. The results of this study suggest, however, that these patients are not characterized by a distinct psychosocial profile. In comparison to healthy controls, PSF-patients reported high psychosocial distress, high positive social support, and low problem-focused coping. However, compared to other chronic patient groups, we found no marked discrepancies with regard to distress, coping styles, social support, and selfefficacy. Moreover, independent associations with fatigue were only found for SCL-Somatic Complaints with CIS-f $(r=.54 ; P<.001)$ and SCL-Obsessive Compulsive with FSS $(r=.35 ; P<.001)$, but not for any other psychosocial variable or stroke characteristic (e.g., time since stroke, single versus recurrent, nature of lesion, and lesion side).

The subscale Obsessive Compulsive of the SCL might mimic the direct neurological consequences of stroke, since it includes items such as "trouble with thinking," "mental slowness," "needing to check things" and "thinking things over." Although no direct association between fatigue severity and severity of cognitive deficits has been found $[4,5,14]$, a relationship between fatigue and cognitive complaints, such as mental slowness, has been substantiated $[13,39]$.

A probable cause for the experienced fatigue may be found in this light. Cognitive deficits may temporarily be compensated for by exerting increased mental effort, which then may cause fatigue [40]. Indeed, widespread brain activity has been shown in patients with unilateral lesions of one cerebral hemisphere trying to perform a unimanual task with their affected hand [41]. Such activities typically require a great amount of attentional resources, because subjects act at the limits of (or even beyond) their functional capacities [42]. A parallel can be drawn from studies of traumatic brain injury where affected individuals showed more dispersion and more brain regions activated when engaged in an attention task than healthy controls [43, 44].

Thus, PSF might be associated with underlying cognitive mechanisms that are independent of the extent of the brain lesion and of psychopathological problems related or unrelated to stroke. If this notion is valid, it would be consistent with the finding that fatigue is almost as frequent in relatively mildly affected patients as in the more severely affected ones $[4,5]$, because it will become a problem whenever subjects try to overcome their individual subtle or severe limits. As soon as subjects are able to deal with their functional limitations more effectively, taking into account their limited attentional capacity and mental energy, fatigue may gradually become less severe.

The association between fatigue and somatic complaints could also be seen in line with this hypothesis. Somatic complaints may reflect the direct physical consequences of stroke, causing functional limitations and/or pain, requiring more task-related physical and mental effort and thereby provoking fatigue. Another part of the somatic complaints could be explained as the physical expression of fatigue. For 
example, many patients report a heavy feeling in arms and legs, nausea, or headaches when becoming tired.

As in previous studies, we first found an association between depression and fatigue on one of our fatigue scales [2, 5-7, 11-14]. However, this association was subordinated to somatic complaints in the regression analysis. A variant of this moderating effect has been previously reported in a study wherein the association between fatigue and depression became weaker, when controlled for by sickness and impact on ambulation [6]. This finding emphasizes not only the dissociation of fatigue and depression, but also the need to assess physical complaints in depth.

A rather unexpected but noteworthy finding of this study was that both fatigue measurements used, the FSS and CIS-f, were associated with completely different variables as shown in Table 3. The use of more than one fatigue scale in clinical practice and research might therefore be warranted.

This study holds several limitations. Due to its crosssectional design we are unable to infer causal relationships. Furthermore, our inclusion criteria restricted the variability of fatigue and mobility, thereby possibly lowering associations. The exclusion of patients with severe cognitive deficits, depression and motor problems might be considered both a strength and a limitation of this study. The major limitation is that it precludes generalization to other stroke patients. On the other hand, this choice enabled us to single out the relationship between fatigue and psychosocial factors, without the influence of these confounding factors.

\section{Conclusions and Implications for Treatment}

By comparing our study group to other reference groups, PSF patients displayed a "normal chronic patient" psychosocial profile. Only cognitive and somatic complaints were associated directly with fatigue. We therefore propose that (a part of) the fatigue might be a consequence of the inadequate adaptation to diminished and or less efficient attentional resources after stroke.

Our findings suggest the following implications for treatment. Somatic complaints should be directly addressed, whenever possible. Graded physical activity programs might be an important contribution to the treatment of PSF, since exercise has been found to be helpful in improving physical and functional outcomes and to reduce fatigue in various other medical conditions $[45,46]$. Such programs might help stroke patients to gradually increase physical activity without experiencing distressing bodily symptoms.

Second, cognitive compensation strategies circumventing the limited energetic resources available to patients suffering from PSF might also be beneficial. These compensation strategies could entail an enhanced planning and variation of activities to foster a more regular pattern of activity and rest [14]. Here, patient education and goal setting could be added to improve patient motivation and adherence [47].

Third, since symptoms of depression and anxiety are common in PSF patients, it is important to address these when present, since they may compromise self-management
[48]. An augmented form of cognitive behavioral therapy, as proposed by Broomfield et al., 2010, [49], is a good starting point to address these issues. It takes into account cognitive deficits and grievance of loss of abilities and could also aid in implementing the behavioral changes needed to apply compensation strategies. Lastly, our results point to the use of more than one scale to assess PSF, highlighting that fatigue is not only a common but also a complex and multifaceted syndrome.

\section{Conflict of Interests}

None of the authors have reported any conflict of interests and all worked independent from the funding source.

\section{Acknowledgment}

This study was supported by The Netherlands Organization of Health Research and Development (ZonMw).

\section{References}

[1] F. Staub and J. Bogousslavsky, "Fatigue after stroke: a major but neglected issue," Cerebrovascular Diseases, vol. 12, no. 2, pp. 75-81, 2001.

[2] K. Jaracz, L. Mielcarek, and W. Kozubski, "Clinical and psychological correlates of poststroke fatigue," Polish Journal of Neurology and Neurosurgery, vol. 41, no. 1, pp. 36-43, 2007.

[3] M. H. De Groot, S. J. Phillips, and G. A. Eskes, "Fatigue associated with stroke and other neurologic conditions: implications for stroke rehabilitation," Archives of Physical Medicine \& Rehabilitation, vol. 84, no. 11, pp. 1714-1720, 2003.

[4] A. Lerdal, L. Bakken, S. Kouwenhoven et al., "Poststroke fatigue-a review," Journal of Pain and Symptom Management, vol. 38, no. 6, pp. 928-949, 2009.

[5] V. Schepers, A. Visser-Meily, M. Ketelaar, and E. Lindeman, "Poststroke fatigue: course and its relation to personal and stroke-related factors," Archives of Physical Medicine and Rehabilitation, vol. 87, no. 2, pp. 184-188, 2006.

[6] S. P. van der Werf, H. L. van den Broek, H. W. Anten, and G. Bleijenberg, "Experience of severe fatigue long after stroke and its relation to depressive symptoms and disease characteristics," European Neurology, vol. 45, no. 1, pp. 28-33, 2001.

[7] E. L. Glader, B. Stegmayr, and K. Asplund, "Poststroke fatigue: a 2-year follow-up study of stroke patients in Sweden," Stroke, vol. 33, no. 5, pp. 1327-1333, 2002.

[8] E. McGeough, A. Pollock, L. N. Smith et al., "Interventions for post-stroke fatigue," Cochrane Database of Systematic Reviews, no. 3, Article ID CD007030, 2009.

[9] F. Staub and A. Carota, "Depression and fatigue after stroke," in Recovery after Stroke, M. P. Barnes, B. H. Dobkin, and J. Bougousslavsky, Eds., pp. 556-597, Cambridge University Press, New York, NY, USA, 2005.

[10] J. B. Cantor, T. Ashman, W. Gordon et al., "Fatigue after traumatic brain injury and its impact on participation and quality of life," Journal of Head Trauma Rehabilitation, vol. 23, no. 1, pp. 41-51, 2008.

[11] S. Choi-Kwon, S. W. Han, S. U. Kwon, and J. S. Kim, "Poststroke fatigue: characteristics and related factors," Cerebrovascular Diseases, vol. 19, no. 2, pp. 84-90, 2005. 
[12] W. K. Tang, Y. K. Chen, V. Mok et al., "Acute basal ganglia infarcts in poststroke fatigue: an MRI study," Journal of Neurology, vol. 257, no. 2, pp. 178-182, 2010.

[13] K. Koopman, M. Uyttenboogaart, P. C. Vroomen, J. van der Meer, J. De Keyser, and G. J. Luijckx, "Long-term sequelae after cerebral venous thrombosis in functionally independent patients," Journal of Stroke and Cerebrovascular Diseases, vol. 18, no. 3, pp. 198-202, 2009.

[14] J. Y. Park, M. H. Chun, S. H. Kang, J. A. Lee, B. R. Kim, and M. J. Shin, "Functional outcome in poststroke patients with or without fatigue," American Journal of Physical Medicine and Rehabilitation, vol. 88, no. 7, pp. 554-558, 2009.

[15] G. Gainotti and C. Marra, "Determinants and consequences of post-stroke depression," Current Opinion in Neurology, vol. 15, no. 1, pp. 85-89, 2002.

[16] A. J. Noble, S. Baisch, A. D. Mendelow, L. Allen, P. Kane, and T. Schenk, "Posttraumatic stress disorder explains reduced quality of life in subarachnoid hemorrhage patients in both the short and long term," Neurosurgery, vol. 63, no. 6, pp. 1095-1104, 2008.

[17] L. Fasotti, "Effectiveness of cognitive and graded activity training (COGRAT) on post stroke fatigue. A multi-center study," 2008, . http://www.onderzoekinformatie.nl/nl/oi/nod/ onderzoek/OND1326577/.

[18] J. H. Vercoulen, C. M. Swanink, J. F. Fennis, J. M. Galama, J. W. van der Meer, and G. Bleijenberg, "Dimensional assessment of chronic fatigue syndrome," Journal of Psychosomatic Research, vol. 38, no. 5, pp. 383-392, 1994.

[19] M. D. Lezak, Neuropsychological Assessment, Oxford University Press, Oxford, UK, 4th edition, 2004.

[20] D. V. Sheehan, Y. Lecrubier, K. H. Sheehan et al., "The mini-international neuropsychiatric interview (M.I.N.I.): the development and validation of a structured diagnostic psychiatric interview for DSM-IV and ICD-10," Journal of Clinical Psychiatry, vol. 59, supplement 20, no. 20, pp. 22-33, 1998.

[21] C. Collin and D. Wade, "Assessing motor impairment after stroke: a pilot reliability study," Journal of Neurology Neurosurgery and Psychiatry, vol. 53, no. 7, pp. 576-579, 1990.

[22] I. J. van Nes, S. van der Linden, H. T. Hendricks et al., "Is visuospatial hemineglect really a determinant of postural control following stroke? An acute-phase study," Neurorehabilitation and Neural Repair, vol. 23, no. 6, pp. 609-614, 2009.

[23] B. Kollen, I. van de Port, E. Lindeman, J. Twisk, and G. Kwakkel, "Predicting improvement in gait after stroke a longitudinal prospective study," Stroke, vol. 36, no. 12, pp. 2676-2680, 2005.

[24] I. van de Port, G. Kwakkel, M. Bruin, and E. Lindeman, "Determinants of depression in chronic stroke: a prospective cohort study," Disability and Rehabilitation, vol. 29, no. 5, pp. 353-358, 2007.

[25] L. B. Krupp, N. G. LaRocca, J. Muir-Nash, and A. D. Steinberg, "The fatigue severity scale. Application to patients with multiple sclerosis and systemic lupus erythematosus," Archives of Neurology, vol. 46, no. 10, pp. 1121-1123, 1989.

[26] L. Whitehead, "The measurement of fatigue in chronic illness: a systematic review of unidimensional and multidimensional fatigue measures," Journal of Pain and Symptom Management, vol. 37, no. 1, pp. 107-128, 2009.

[27] A. S. Zigmond and R. P. Snaith, "The hospital anxiety and depression scale," Acta Psychiatrica Scandinavica, vol. 67, no. 6, pp. 361-370, 1983.

[28] R. Whelan-Goodinson, J. Ponsford, and M. Schonberger, "Validity of the hospital anxiety and depression scale to assess depression and anxiety following traumatic brain injury as compared with the structured clinical interview for DSM-IV," Journal of Affective Disorders, vol. 114, no. 1-3, pp. 94-102, 2009.

[29] W. A. Arrindell and H. Ettema, "Dimensionele structuur, betrouwbaarheid en validiteit van de nederlandse bewerking van de symptom checklist (SCL-90): gegevens gebaseerd op een fobische en een normale populatie," Nederlands Tijdschrift Voor de Psychologie en Haar Grensgebieden, vol. 36, no. 2, pp. 77-108, 1981 (Dutch).

[30] D. Hoofien, O. Barak, E. Vakil, and A. Gilboa, "Symptom checklist-90 revised scores in persons with traumatic brain injury: affective reactions or neurobehavioral outcomes of the injury?" Applied Neuropsychology, vol. 12, no. 1, pp. 30-39, 2005.

[31] V. Starcevic, G. Bogojevic, and J. Marinkovic, "The SCL-90-R as a screening instrument for severe personality disturbance among outpatients with mood and anxiety disorders," Journal of Personality Disorders, vol. 14, no. 3, pp. 199-207, 2000.

[32] D. T. D. de Ridder, G. L. van Heck, N.S. Endler, and J. D. A. Parker, Coping Inventory for Stressful Situations CISS, Swetz \& Zeitlinger/ Harcourt, Lisse, The Netherlands, 2004.

[33] G. I. J. M. Kempen and L. M. Van Eijk, "The psychometric properties of the SSL12-I, a short scale for measuring social support in the elderly," Social Indicators Research, vol. 35, no. 3, pp. 303-312, 1995.

[34] B. De Vree, S. van de Werf, J. Prins et al., "Meetinstrumenten bij chronische vermoeidheid," Gedragstherapie, vol. 35, pp. 157-164, 2002 (Dutch).

[35] P. Spinhoven, J. Ormel, P. P. Sloekers, G. I. Kempen, A. E. Speckens, and A. M. Van Hemert, "A validation study of the hospital anxiety and depression scale (HADS) in different groups of Dutch subjects," Psychological Medicine, vol. 27, no. 2, pp. 363-370, 1997.

[36] F. L. P. Sonderen, "Het meten van sociale steun met de Sociale Steun Lijs," Interacties (SSL-I)-Discrepanties (SSL-D) een handleiding, 1993 (in Dutch).

[37] J. B. Prins, G. Bleijenberg, E. Bazelmans et al., "Cognitive behaviour therapy for chronic fatigue syndrome: a multicentre randomised controlled trial," The Lancet, vol. 357, no. 9259, pp. 841-847, 2001.

[38] Y. Benjamini and Y. Hochberg, "Controlling the false discovery rate: a practical and powerful approach to multiple testing," Journal of the Royal Statistical Society B, vol. 51, pp. 289-300, 1995.

[39] I. Winkens, C. M. Van Heugten, L. Fasotti, and D. T. Wade, "Reliability and validity of two new instruments for measuring aspects of mental slowness in the daily lives of stroke patients," Neuropsychological Rehabilitation, vol. 19, no. 1, pp. 64-85, 2009.

[40] A. H. Van Zomeren, W. H. Brouwer, and B. G. Deelman, "Attentional deficits: the riddles of selectivity, speed and alertness," in Closed Head Injury: Psychological, Social and Family Consequences, D. Brooks, Ed., pp. 398-415, Oxford University Press, Oxford, UK, 1984.

[41] C. A. Hanlon, A. L. Buffington, and M. J. McKeown, "New brain networks are active after right MCA stroke when moving the ipsilesional arm," Neurology, vol. 64, no. 1, pp. 114-120, 2005.

[42] J. P. Regnaux, D. David, O. Daniel, D. B. Smail, M. Combeaud, and B. Bussel, "Evidence for cognitive processes involved in the control of steady state of walking in healthy subjects and after cerebral damage," Neurorehabilitation and Neural Repair, vol. 19, no. 2, pp. 125-132, 2005. 
[43] C. Christodoulou, J. DeLuca, J. H. Ricker et al., "Functional magnetic resonance imaging of working memory impairment after traumatic brain injury," Journal of Neurology Neurosurgery and Psychiatry, vol. 71, no. 2, pp. 161-168, 2001.

[44] M. Maruishi, M. Miyatani, T. Nakao, and H. Muranaka, "Compensatory cortical activation during performance of an attention task by patients with diffuse axonal injury: a functional magnetic resonance imaging study," Journal of Neurology, Neurosurgery and Psychiatry, vol. 78, no. 2, pp. 168173, 2007.

[45] H. Gonzalez, T. Olsson, and K. Borg, "Management of postpolio syndrome," The Lancet Neurology, vol. 9, no. 6, pp. 634-642, 2010.

[46] M. Edmonds, H. McGuire, and J. Price, "Exercise therapy for chronic fatigue syndrome," Cochrane Database of Systematic Reviews, no. 3, Article ID CD003200, 2004.

[47] B. A. Wilson, F. Gracey, J. J. Evans, and A. Bateman, Neuropsychological Rehabilitation, Cambridge University Press, Cambridge, Mass, USA, 2009.

[48] D. de Ridder, R. Geenen, R. Kuijer, and H. van Middendorp, "Psychological adjustment to chronic disease," The Lancet, vol. 372, no. 9634, pp. 246-255, 2008.

[49] N. Broomfield, K. Laidlaw, E. Hickabottom et al., "Poststroke depression: the case for augmented, individually tailored cognitive behavioural therapy," Clinical Psychology and Psychotherapy, vol. 18, no. 3, pp. 202-217, 2010. 


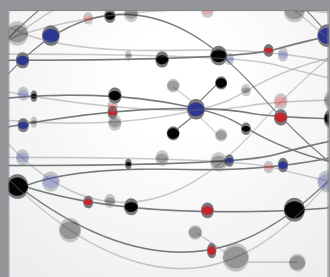

The Scientific World Journal
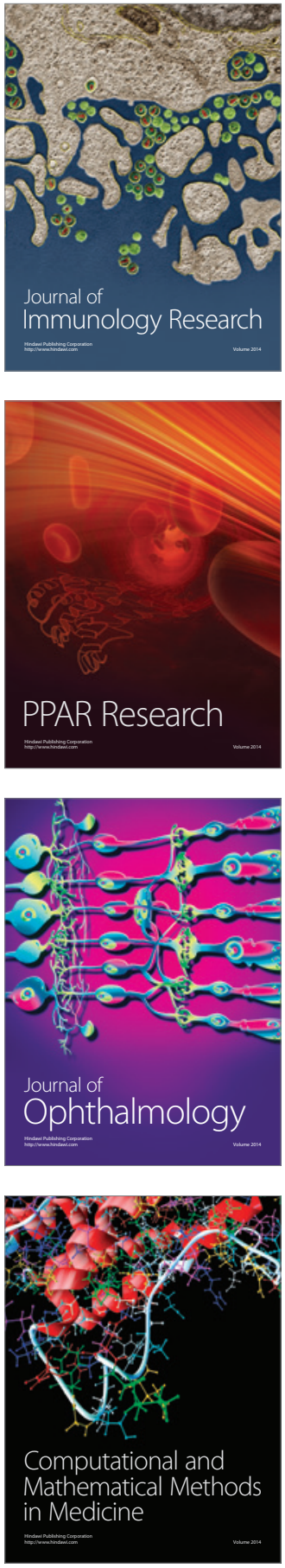

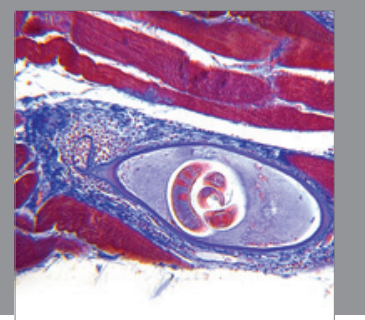

Gastroenterology

Research and Practice
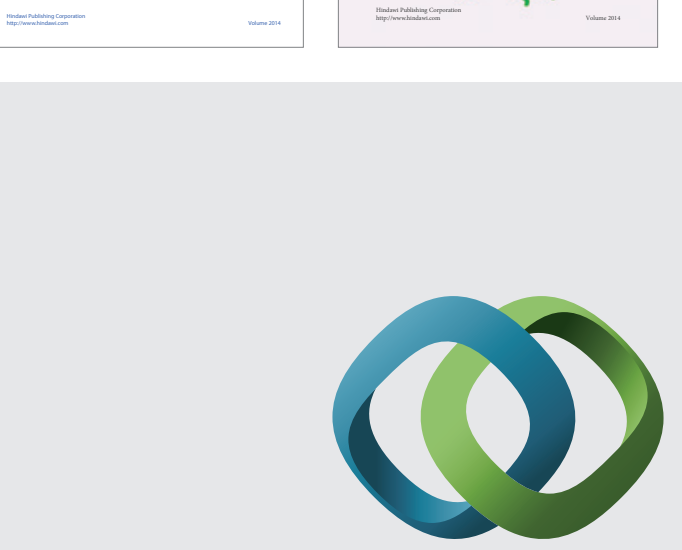

\section{Hindawi}

Submit your manuscripts at

http://www.hindawi.com
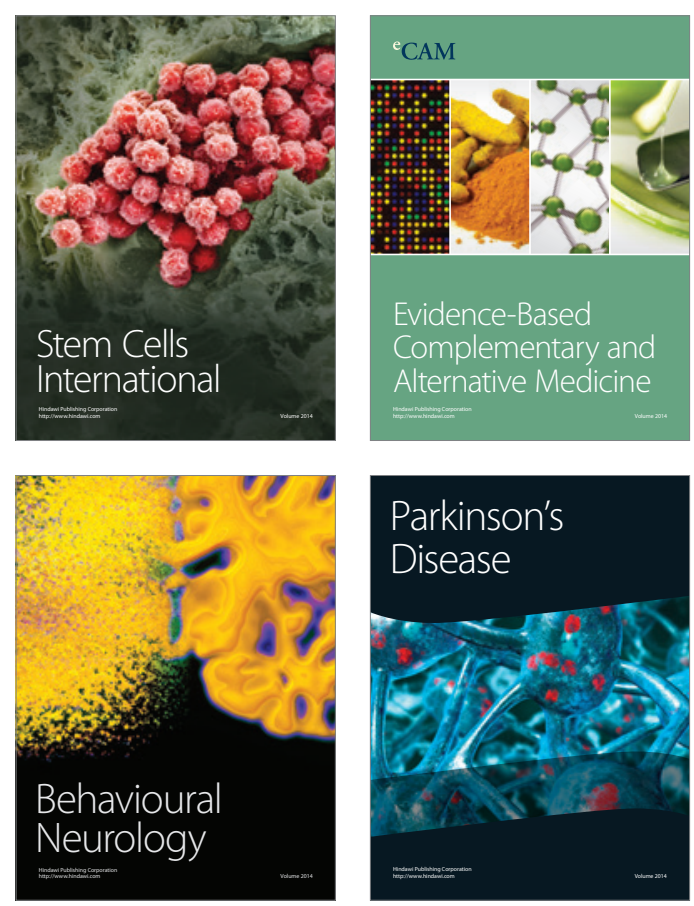

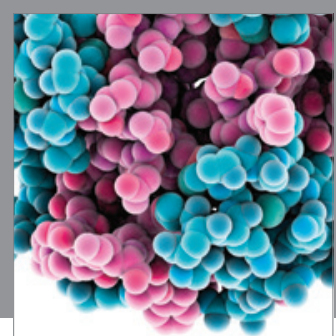

Journal of
Diabetes Research

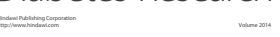

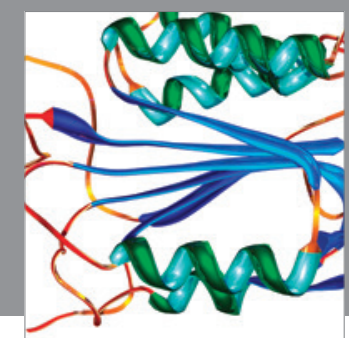

Disease Markers
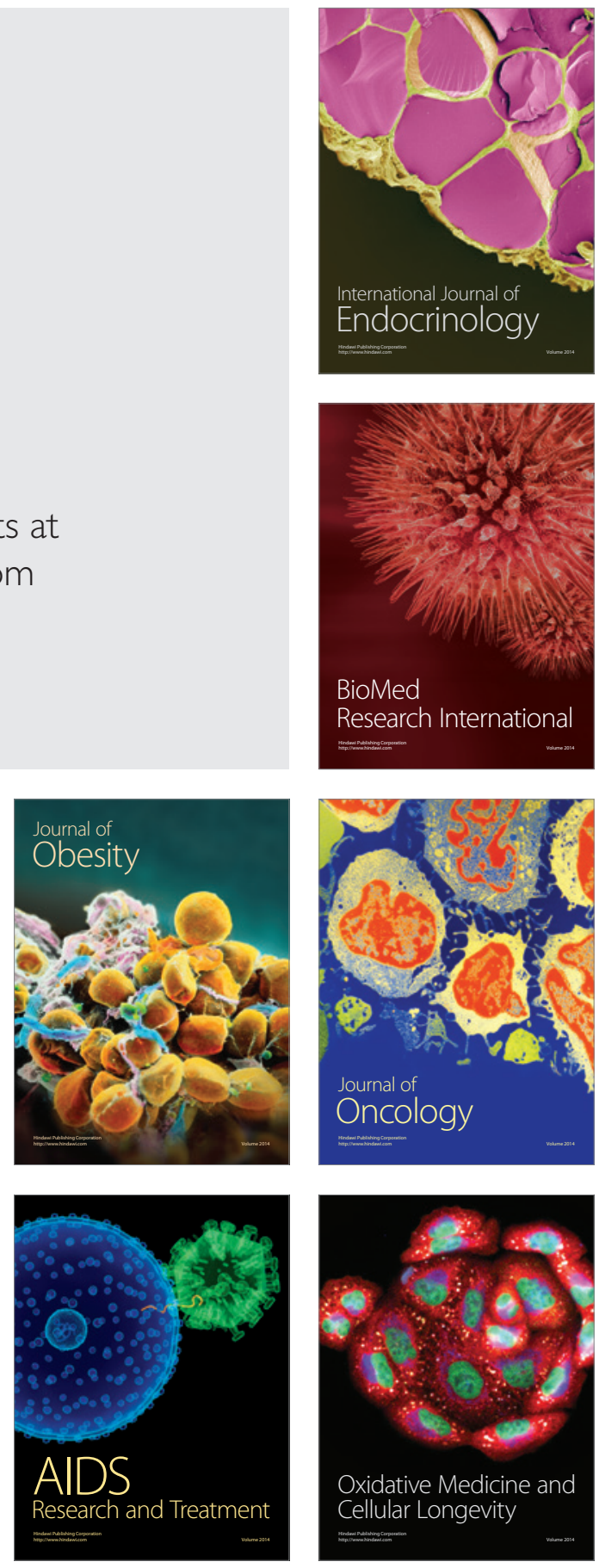